\title{
Review Article \\ Proanthocyanidins against Oxidative Stress: From Molecular Mechanisms to Clinical Applications
}

\author{
Lingyu Yang $\mathbb{D}^{1},{ }^{1}$ Dehai Xian, ${ }^{2}$ Xia Xiong, ${ }^{1}$ Rui Lai, ${ }^{1}$ Jing Song $\mathbb{D},{ }^{1}$ and Jianqiao Zhong ${ }^{1}$ \\ ${ }^{1}$ Department of Dermatology, The Affiliated Hospital of Southwest Medical University, Luzhou 646000, China \\ ${ }^{2}$ Department of Anatomy, Southwest Medical University, Luzhou 646000, China \\ Correspondence should be addressed to Jianqiao Zhong; zjq7632@hotmail.com
}

Lingyu Yang and Dehai Xian contributed equally to this work.

Received 11 December 2017; Accepted 14 January 2018; Published 12 March 2018

Academic Editor: Yan Huang

Copyright (C) 2018 Lingyu Yang et al. This is an open access article distributed under the Creative Commons Attribution License, which permits unrestricted use, distribution, and reproduction in any medium, provided the original work is properly cited.

\begin{abstract}
Proanthocyanidins (PCs) are naturally occurring polyphenolic compounds abundant in many vegetables, plant skins (rind/bark), seeds, flowers, fruits, and nuts. Numerous in vitro and in vivo studies have demonstrated myriad effects potentially beneficial to human health, such as antioxidation, anti-inflammation, immunomodulation, DNA repair, and antitumor activity. Accumulation of prooxidants such as reactive oxygen species (ROS) exceeding cellular antioxidant capacity results in oxidative stress (OS), which can damage macromolecules (DNA, lipids, and proteins), organelles (membranes and mitochondria), and whole tissues. OS is implicated in the pathogenesis and exacerbation of many cardiovascular, neurodegenerative, dermatological, and metabolic diseases, both through direct molecular damage and secondary activation of stress-associated signaling pathways. PCs are promising natural agents to safely prevent acute damage and control chronic diseases at relatively low cost. In this review, we summarize the molecules and signaling pathways involved in OS and the corresponding therapeutic mechanisms of PCs.
\end{abstract}

\section{Introduction}

For centuries, natural plant extracts have been used to prevent and treat a variety of clinical diseases. Proanthocyanidins (PCs) are ubiquitous in fruits, seeds, cereals, bark, flowers, nuts, and vegetables. PCs function as powerful scavengers of oxygen free radicals, with potency comparable to vitamins $\mathrm{C}$ and $\mathrm{E}[1,2]$. In addition, emerging evidence indicates that PCs target deleterious signaling pathways activated downstream of free radical production.

Under normal physiological conditions, the endogenous antioxidative system maintains a dynamic redox equilibrium, which is vital to many of the molecular cascades contributing to differentiation, metabolism, proliferation, and apoptosis [3]. However, excessive generation of reactive nitrogen species (RNS) and reactive oxygen species (ROS) with ensuing hyperactivation of redox-regulated protein signaling networks induce oxidative stress (OS), which is a central self-sustaining pathogenic process in various diseases of otherwise distinct etiology [4]. During disease progression, various inflammatory mediators and cytokines [e.g., nitric oxide (NO), prostaglandins, tumor necrosis factor- $\alpha$ (TNF$\alpha$ ), interleukin (IL)-1, and IL-6] produced by macrophages, neutrophils, and lymphocytes can exacerbate OS [5]. OS damages proteins, DNA, and lipids, ultimately resulting in tissue dysfunction [6]. Indeed, many neurodegenerative disorders, inflammatory diseases, cardiovascular diseases, and metabolic disorders involve OS [7-11].

Several lines of evidence have shown that natural dietary antioxidants are effective for disease prevention and treatment. Some of these antioxidants are direct free radical scavengers, whereas others such as PCs can attenuate OS both by scavenging free radicals and by modifying signaling pathways, including those involving nuclear factor erythroid 2-related factor 2 (Nrf2), mitogen-activated protein kinase (MAPK), nuclear factor-kappaB (NF- $\kappa \mathrm{B})$, and phosphoinositide 3-kinase (PI3K)/Akt [12]. The antioxidant efficacy of PCs has been verified in human, animal, and culture studies, which collectively demonstrate the potential of PCs for prevention or treatment of OS-associated diseases [13-15]. 


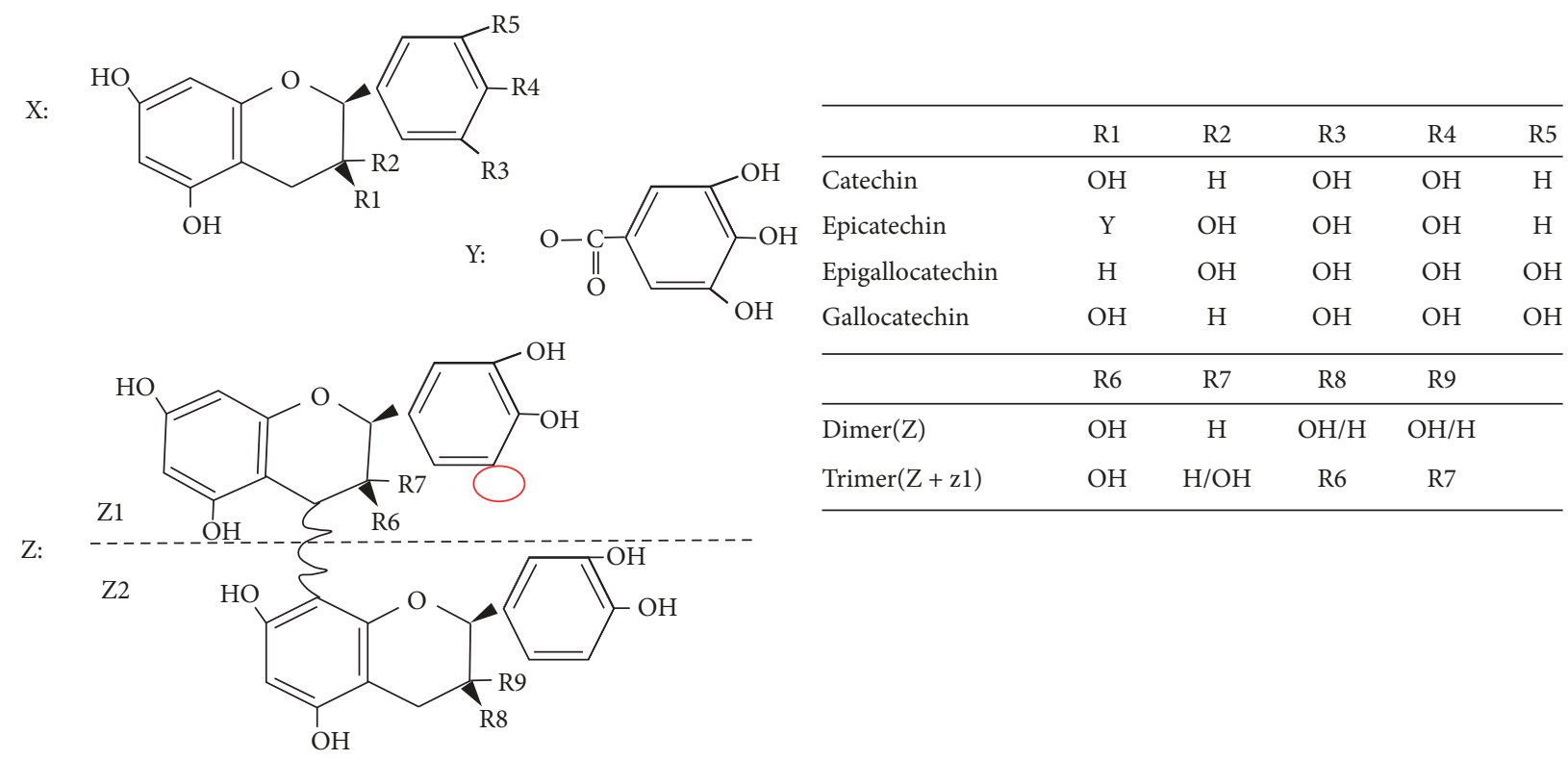

Figure 1: The stereochemical structure and forms of PCs. X represents the universal structure of flavan-3-ol units in PCs; Y indicates that the subunit is part of a constituent monomer; $\mathrm{Z}$ represents the basic structure of OPCs and PPCs. Z1 combines repeatedly with Z2 to form polymeric PCs.

Further, PCs are easily extracted, are affordable, and demonstrate low toxicity [16]. Identification of molecular events and signaling pathways involved in the antioxidant mechanism of specific PCs is crucial for further clinical applications.

\section{Structure, Distribution, and Chemical Characteristics of PCs}

2.1. Stereochemical Structure and Forms. PCs consist of chains of epicatechin, catechin, gallocatechin, or epigallocatechin subunits doubly linked through C4-C6 and C4-C8 interflavanoid bonds [17-19]. PCs that are consisting mainly of epicatechin monomers, called procyanidins, are the most abundant form. Less common PCs containing epigallocatechin subunits are designated prodelphinidins [20]. Usually, PCs with a lower degree of polymerization (two to four monomers) are named oligomeric PCs (OPCs), whereas those with more than five monomers are called polymeric PCs (PPCs) [21]. In addition, eight distinct structures of PCs dimers and trimers have been identified (B1-B8), which are designated $\mathrm{C} n$ (where $n=1,2, \ldots$ ) according to the different component monomers and positions of the connected carbon atoms [22, 23]. Figure 1 illustrates the stereochemical structure and different forms of PCs.

2.2. Distribution in Plants. In 1967, Joslyn et al. isolated four polyphenolic compounds from grape peel and seed extracts and found that these compounds could produce anthocyanidins through the cleavage of interflavan bonds using acidic butanol solution $(\mathrm{n}-\mathrm{BuOH} / \mathrm{HCl}, 95: 5)$ in the presence of iron (III) salts and heat $\left(95^{\circ} \mathrm{C}\right)$, which are called PCs [24, 25]. Many subsequent studies were conducted to investigate the distribution and functions of these and additional PCs. Afterwards,
PCs with distinct structures and subunit compositions have been isolated in different relative proportions from numerous fruits, seeds, peels, leaves, flowers, roots, and stems (Table 1) [26], including common dietary species such as grapes, apples, lychee, blackberry, and blueberry.

2.3. Metabolism, Features, and Functions. PCs monomers are extensively conjugated in the liver and then released to either circulate in the body before excretion in urine or accumulate in tissues, partly returning to the intestine via the bile $[28,29]$. Dimers and some trimers may be absorbed in the small intestine [30], but most ingested PCs are extensively depolymerized and absorbed as monomers or metabolized by the gut microbiota before passing through the colon [31]. The absorptivity of a given PC depends on its specific molecular structure; thus, molecular structure markedly influences bioavailability and function. Monomeric PCs are more absorbable than dimeric PCs. Small-molecule PCs, such as catechin monomers, tend to be easily absorbed, whereas PCs with large (-)-epigallocatechin-3-gallate molecules are poorly absorbed through the gut barrier [32, 33]. Moreover, other plant constituents consumed with PCs, such as carbohydrates, proteins, and fiber, may have synergic or antagonistic effects on PCs absorption and bioavailability $[34,35]$. In some instances, poor absorption can actually contribute to efficacy against infectious diseases; for example, the benefits of PCs against urinary tract infections may occur via the interactions at the gastrointestinal tract mucosal surface [36]. In most cases, however, the benefits of small-molecule PCs (antioxidation, immunomodulation, anti-inflammation, antiangiogenesis, and antiproliferation) are dependent on absorption and systemic bioavailability. Thus, small-molecule PCs with high absorption are particularly promising agents for clinical applications [37]. 
TABLE 1: Primary distribution of PCs in various plants [27].

Grape, Brassica campestris, Camellia oleifera, Glycine max var., Oryza, Sorghum vulgare, Theobroma cacao, Vicia faba, Lablab purpureus, Litchi chinensis, Hippophae rhamnoides, Malus pumila, Rubus allegheniensis, Fragaria vesca, Fructus crataegi, Dimocarpus longan, Vaccinium myrtillus, Elaeagnus angustifolia, Oxycoccus, Diospyros kaki, Garcinia mangostana, Punica granatum

Fruit/seeds/peel Fructus crataegi, Leucaena leucocephala cv., Reyan No.1, Ginkgo biloba, Betula platyphylla, Vitis spp., Thea viridis, Scrophularia ningpoensis, Hypericum perforatum, Laurus nobilis, Eucalyptus spp.

Leaves Fructus crataegi, Rosa rugosa, Dimocarpus longan, Pharhiris nil qianniuhua, Ipomoea aquatica, Trifolium pratense, Nymphaea tetragona

Flower Sanguisorba officinalis, Pueraria lobata, Rheum palmatum, Anisophyllea dichostyla, Ipomoea batatas

The antioxidative properties of PCs have been demonstrated in multiple OS-associated diseases [38]. Studies conducted in vitro and in vivo have demonstrated that PCs can effectively resist OS-induced damage and augment cellular antioxidant capacity by direct molecular scavenging and by modulation of various downstream signaling pathways associated with stress responses. Several researchers found that PCs contributed to the prevention of UV-induced skin disorders, diabetic retina injury, or zearalenone-induced liver damage by activating Nrf2 pathway or inhibiting MAPK/NF$\kappa \mathrm{B}$ pathway, by scavenging hydroxyl radicals and superoxide anions, and by upregulating endogenous antioxidants and detoxication enzymes, such as hemeoxygenase1 (HO-1), catalase (CAT), superoxide dismutase (SOD), and glutathione peroxidase (GSH-Px) [39-42]. In addition, Yamakoshi et al. demonstrated that PCs have low toxicity and are safe for dietary administration in rats [43, 44]. Fujii et al. further reported that the PCs constituent Oligonol, found in lychee extract, is safe, nontoxic, and nonmutagenic to healthy humans even at $200 \mathrm{mg} /$ day for three months [45]. Meanwhile, some clinical trials of PCs have been performed for the assessment of safety and the treatment of clinic diseases in healthy subjects and pregnant women, which have demonstrated that daily oral intake of PCs up to $2500 \mathrm{mg}$ is safe in healthy adults and PCs serve as a safe and effective therapy for pregnant women with condyloma acuminata [46, 47]. These results indicate that PCs are safe antioxidants with no apparent side effects and so may be widely utilized in clinical medicine and cosmetology. However, more systematic toxicity tests on PCs are needed to investigate the safety of other constituents and to evaluate their effectiveness in the food ecosystem.

\section{Mechanisms against OS}

OS is essentially a state of redox imbalance originating from relative overproduction of ROS/RNS or decreased antioxidant capacity as indicated by the reduced oxidized glutathione (GSH/GSSG) or NADPH/NADP ${ }^{+}$ratio. OS can result from the overproduction and accumulation of prooxidants such as ROS, lipid peroxides, NO, and superoxide radical $\left(\mathrm{O}_{2}{ }^{-}\right)$or from the relative insufficiency of antioxidant molecules (GSH) and enzymes such as CAT, SOD, and GSH$\mathrm{Px}$ [39]. As the second messenger or signaling molecule, ROS play a key role in the initiation and development of OS $[48,49]$. ROS at low levels are beneficial to cells and tissues (e.g., cell proliferation, tissue repair, and angiogenesis) [5052]; conversely, at high levels ROS contribute to cell damage, apoptosis, and/or death $[53,54]$. Normally, ROS are rapidly detoxified by endogenous antioxidants; however, accumulated ROS can initiate a surge of toxic biochemical reactions that result in direct damage to DNA, lipids, and proteins [55, 56]. Increasing evidence has indicated that ROS have the ability to mediate various signaling pathways (e.g., Nrf2, MAPK, $\mathrm{NF}-\kappa \mathrm{B}$, and PI3K/Akt), ion channels, and transporters and modify protein kinase and ubiquitination/proteasome system $[57,58]$. Although the knowledge of ROS-mediating mechanism is known well, further studies on ROS interacting with signaling pathways are still required. There is now compelling evidence implicating OS and associated signaling pathways in cardiovascular, metabolic, neurodegenerative, and inflammatory diseases, as well as immune diseases [59]. Furthermore, there is also rapidly accumulating evidence that PCs can prevent OS damage by downregulating these same molecular species and signaling pathways [12].

3.1. Repair of DNA Damage. Excessive ROS production during OS can directly induce DNA damage or mutations. For instance, ROS produced by photo-OS reacts with nucleobases or the 2-deoxyribose moiety and results in nuclear DNA oxidative damage through single pyrimidine or purine modification, interchain cross-links, DNA-protein adduct formation, and apurinic/apyrimidinic (AP) site formation. Exposure to UV can induce the formation of highly mutagenic cyclobutane pyrimidine dimers (CPDs) and other free radicals potentially damaging to genomic DNA $[60,61]$. Mitochondrial DNA (mtDNA) is even more susceptible to ROS-mediate mutagenesis and destruction than nuclear DNA due to its proximity to the electron transport chain, a major site of ROS generation, and lack of protective histones $[62,63]$. Primary damage to nuclear DNA and mtDNA facilitates additional mutations, which may ultimately result in chronic diseases and cancers.

PCs have been shown to prevent OS-induced DNA damage and promote DNA repair through the following pathways [64-67]: (1) scavenging oxidative species (e.g., ROS and RNS) and free radicals, thereby disrupting direct OS damage and redox chain reactions; (2) enhancing the functions of DNA repair enzymes; (3) dose-dependently inhibiting CPD formation; (4) rapidly repairing CPDs through the induction of IL12; (5) promoting the nucleotide excision repair mechanism; and (6) inhibiting DNA hypomethylation. 
3.2. Prevention of Lipid Peroxidation. OS-related products attack multiple biomolecules; particularly polyunsaturated fatty acids (PUFAs) are vulnerable, which can result in membrane injury through inactivation of membrane receptors and enzymes, reduced membrane fluidity, increased membrane permeability to ions, and in extreme cases cell membrane rupture and release of organelles [68, 69]. Excessive ROS not only directly damage PUFAs but also initiate a selfperpetuating chain reaction in which lipid peroxides as well as unstable FA radicals are generated and rapidly broken down to form additional FA radicals [70-72]. PCs can stabilize and inactivate free radicals by donating an electron to free radical $-\mathrm{OH}$ groups attached to the phenolic ring, which helps to terminate oxidative chain reactions. Indeed, Mittal et al. found that PC treatment substantially inhibited UVB-induced lipid peroxidation [69, 73]. Moreover, PCs combined with DHA-OR could improve PUFAs, ameliorate lipid hydroperoxides, and increase the detoxification of postprandial xenobiotics in rats liver [74]. In addition, PCs protected against cadmium-induced ROS production, free radical production, and lipid peroxidation in rat erythrocytes and lymphocytes [75].

3.3. Modulation of Signaling Pathways Involved in OS. In addition to oxidation of macromolecules, ROS generated during OS may act as second messengers to activate or inhibit signal pathways that control the expression of downstream stress-responsive genes. Disruption or aberrant activation of these pathways can lead to premature aging, inflammation, and oncogenesis [59]. In the following section, the effects of PCs on OS-related signaling pathways are discussed.

3.3.1. Inhibition of MAPK Pathways. The MAPK family kinases p38 MAPKs, c-Jun amino-terminal kinases (JNKs), and extracellular signal-regulated kinases (ERKs) are important regulators of transcriptional cascades mediating stress responses in cells $[76,77]$, including responses to UV, heat, and toxic chemicals [78]. OS triggers the activation of JNKs, p38 MAPKs, and ERKs through ROS-induced enhancement of phosphorylation, resulting in nuclear translocation and promoting expression of stress-response factors related to OS, cell proliferation/apoptosis, inflammation, and tissue remodeling (such as vascular growth) [79-81]. However, PCs can directly downregulate stress-activated MAPK pathway activities (e.g., IL-17-stimulated ERK, p38, and JNK activities) resulting in suppression of ROS production, OS damage, and apoptosis-related pathways [82]. For instance, PCs not only diminished ethanol-induced ROS generation but also enhanced the expression and activity of antioxidant enzymes via ERK, JNK, and p38 MAPK pathways in both cultured cells and rat liver [83]. In addition, PCs enhanced Nrf2 expression and activated Nfr2 antioxidant response element- (ARE-) mediated transcription via p38 MAPK and PI3K/Akt pathways in HepG2 cells, thereby increasing phase II/antioxidant enzyme expression [84].

3.3.2. Suppression of the NF- $\kappa B$ Pathway. Transcription factor $\mathrm{NF}-\kappa \mathrm{B}$ is activated by multiple cellular stressors (including oxidants and antigens) and in turn regulates the expression of many genes involved in OS, apoptosis, and inflammation [85]. Its target genes mainly encode regulators of the immune/inflammatory response, such as immune receptors (IFN- $\gamma$ receptor, $\mathrm{MHC}$, IL-2 receptor), cytokines (TNF- $\alpha$, IL6, IL-1), adhesion molecules (VCAM-1, ICAM-1), prooxidant enzymes (COX-2, iNOS), and chemokines (MCP-1, MIP- $1 \alpha$, IL-8). NF- $\kappa$ B also enhances the transcription of antioxidant enzymes and antiapoptotic proteins [86]. Normally, NF$\kappa \mathrm{B}$ proteins are retained in the cytoplasm through interactions with $\mathrm{NF}-\kappa \mathrm{B}$ inhibitory proteins (I $\kappa \mathrm{Bs}$ ); under OS, however, $\mathrm{I} \kappa \mathrm{B} s$ are phosphorylated, dissociated from NF- $\kappa \mathrm{B}$, and degraded, allowing NF- $\kappa \mathrm{B}$ translocation into the nucleus [87]. MAPKs signals are important upstream regulators of the $\mathrm{NF}-\kappa \mathrm{B}$ pathway [88]. PCs can reduce OS damage and inflammation by suppressing NF- $\kappa \mathrm{B}, \mathrm{ERK}$, p38, and JNK phosphorylation. Via blocking NF- $\kappa$ B and MAPK pathways, PCs in turn inhibit the mRNA expression of proinflammatory cytokines like TNF- $\alpha$ and IL- $1 \beta$ as well as the inflammatory prostaglandin products of COX-2 $[89,90]$. In addition, PCs can suppress the replication of respiratory syncytial virus (RSV) by blocking RSV-induced NF- $\kappa$ B, p38 MAPK/JNK, AP-1, and ERK activities [91].

3.3.3. Activation of Nrf2 Pathways. Nrf2 is a crucial transcriptional regulator in OS and facilitates the expression of cytoprotective genes in response to OS. Under normal conditions, Nrf2 remains in an inactive cytoplasmic form through binding to Kelch-like ECH associating protein 1 (Keap1), which facilitates Nrf2 degradation [92]. OS triggers Nrf2-Keap1 dissociation and Nrf2 nuclear translocation, where it binds to the AREs and promotes activation of various antioxidant enzymes/proteins [93-95] such as HO-1, phase II detoxification enzymes peroxiredoxin 1, glutamatecysteine ligase catalytic subunit, and $\mathrm{NAD}(\mathrm{P}) \mathrm{H}$ quinone dehydrogenase 1 (NQO1) [96, 97]. PCs can induce Nrf2 expression and ARE-mediated transcription [84], thereby reducing OS. For instance, PCs inhibited lead-induced liver OS damage and elevated antioxidant capacity via activation of Nrf2/ARE signaling [98]. Oligomeric PCs also markedly enhanced the nuclear translocation of Nrf2, promoted the expression of HO-1, NQO1 and thioredoxin reductase 1, and suppressed $\mathrm{H}_{2} \mathrm{O}_{2}$-induced OS damage in A549 cells [99].

3.3.4. Regulation of Other Signaling Pathways. The Janus kinase-signal transducer and activator of transcription (JAK/STAT) pathway is another important regulator of inflammatory factors and cytokines associated with OS. The JAK/STAT pathway is activated by ROS and hypoxia/reperfusion or osmotic stress through binding of induced cytokines to their specific receptors [100, 101]. The PI3K/Akt pathway also regulates OS and cell proliferation, and abnormalities in this pathway have been implicated in the initiation and progression of cancer [102]. PCs may prevent apoptosis and alleviate neurological impairment in type 2 diabetes (T2D) model Sprague-Dawley rats with focal cerebral ischemia by decreasing STAT1 expression and inhibiting JAK/STAT signaling [103]. PCs also inhibited 


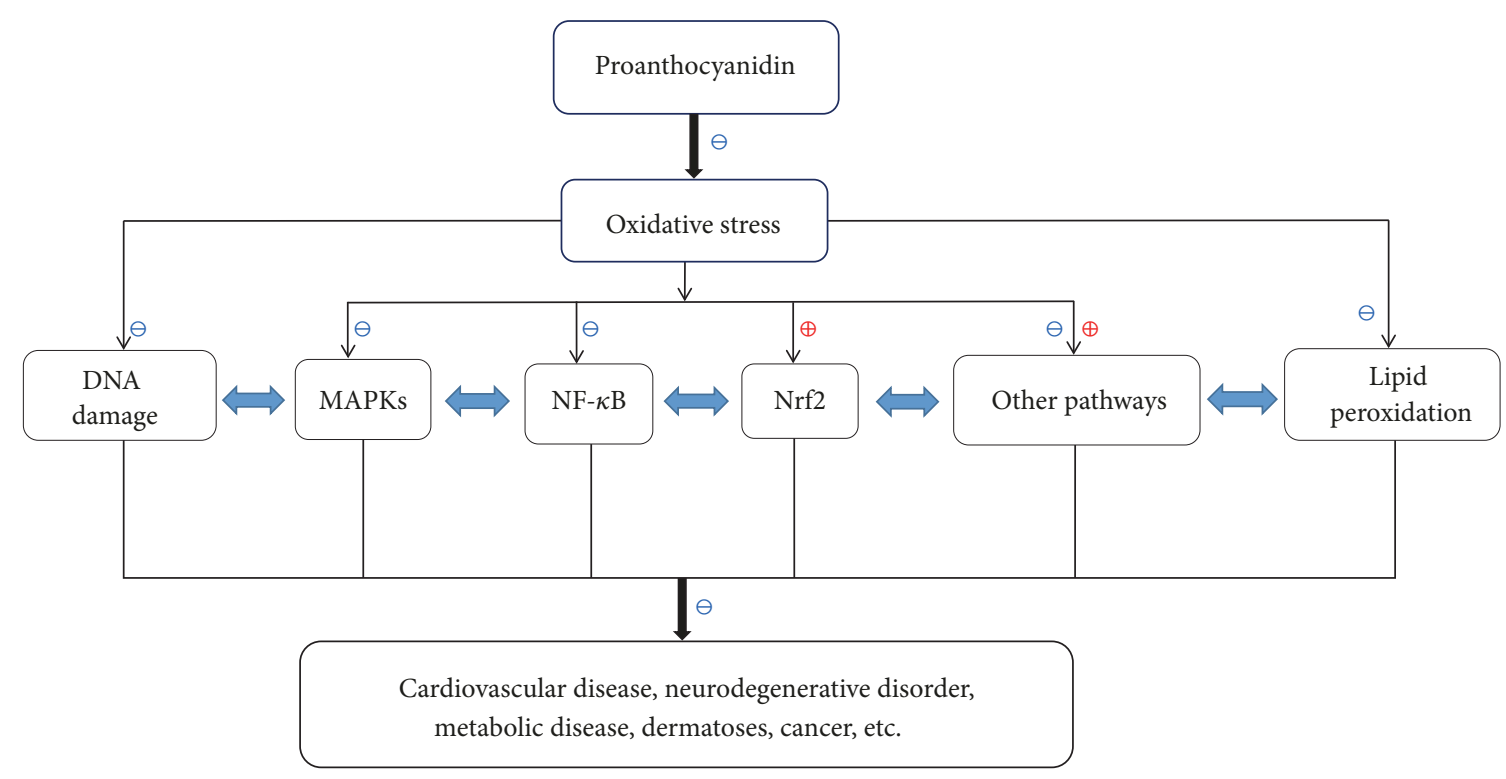

FIGURE 2: PCs control OS-related diseases via mediating several molecular targets and signaling pathways. PCs effectively suppress OS through repairing DNA damage, preventing lipid peroxidation, and modulating signaling pathways (e.g., Nrf2, MAPKs, NF-kB pathways) and, further, treat OS-related diseases like cardiovascular diseases, neurodegenerative disorders, metabolic diseases, skin disorders, and cancer. $\oplus$ means "to promote or enhance"; $\ominus$ means "to inhibit or suppress."

high glucose-induced vascular smooth muscle cell growth by blocking the PI3k/Akt-dependent signaling pathway and ROS overproduction [104].

The many pathways and factors involved in OS seldom work in isolation. For example, STAT1 can be directly phosphorylated by $\mathrm{p} 38$ MAPK in vitro, which implies that MAPKs and STAT are convergent pathways regulating OS [105]. Similarly, PI3K and MAPK pathways influence Nrf2 transcription and phase II detoxifying/antioxidant enzymes expression [106, 107]. Therefore, PCs may alleviate and control OS by mediating broad OS-associated pathways via targeting specific signaling nodes (Figure 2). Further, individual structurally distinct PCs may exert diverse therapeutic effects depending on structure. This property may enable the same PCs extract to suppress multiple etiologically distinct OS-related clinical disorders.

\section{Clinical Applications of PCs for OS-Related Diseases}

Clinical and experimental evidence implicate that OS is in numerous acute/chronic diseases including cardiovascular, neurodegenerative, metabolic, and inflammatory disorders [59]. Owing to antioxidant efficacy, PCs may be powerful clinical tools for the management of these diseases.

4.1. Cardiovascular Diseases. There is substantial evidence for PC efficacy against cardiovascular diseases. OS is believed to be an essential mechanism in the pathogenesis of cardiovascular diseases and vasculopathies such as atherosclerosis, hypertension, heart failure, and restenosis after angioplasty $[9,108]$. ROS disrupt myocardial calcium homeostasis, which can lead to arrhythmia and cardiac remodeling by aberrant induction of various signaling pathways and gene expression cascades [109]. ROS-mediated lipid peroxidation contributes to the initiation and progression of atherosclerosis [110]. Deoxycorticosterone acetate- (DOCA-) salt promotes the development of hypertension, cardiovascular remodeling, and cardiovascular dysfunction by increasing p 38 MAPK and JNK1/2 phosphorylation. On the contrary, PCs can reduce high blood pressure induced by DOCA-salt and ameliorate cardiovascular remodeling by suppressing ROS generation and p38MAPK pathway activation [111]. Simultaneously, PCs are able to reduce risk factors for cardiovascular diseases by diminishing lipid peroxidation, decreasing blood pressure, and improving hypertriglyceridemia [112].

4.2. Neurodegenerative Disorders. It has been confirmed that PCs provide neuronal protection against degenerative diseases by scavenging ROS [113]. OS is a primary pathogenic mechanism in multiple neurodegenerative diseases, such as Parkinson's disease (PD), amyotrophic lateral sclerosis, Alzheimer's disease (AD), and epilepsy [114]. Lipid peroxidation contributes to a chain reaction implicated in neurotoxicity and neuroinflammation. PUFAs are abundant in the nervous system and prefer to present in neuronal membranes than other cellular membranes [115]. Furthermore, certain species such as the $\omega$-3 LC-PUFA docosahexaenoic acid (DHA) is unique to the nervous system and exquisitely sensitive to OS [116]. The PI3K/Akt signaling pathway plays a protective role in neurodegenerative diseases [117], and PCs can disrupt lipid peroxidation chain reactions to protect neurons through PI3K/Akt signaling pathway modulation $[69,73]$. For instance, PCs protected against cadmiuminduced oxidative neurotoxicity in mouse brain by activating 
Akt phosphorylation and preventing lipid peroxidationdependent membrane damage [118]. Also, PCs offered powerful protection against OS-related DNA damage and lipid peroxidation in AD and PD models [119]. PCs, meanwhile, attenuated neurotoxicity and alleviated neurodegeneration in PD cell models via control of OS progression and preservation of mitochondrial function [120].

4.3. Metabolic Diseases. Metabolic disorders such as obesity, insulin resistance, T2D, hepatic steatosis, and hyperlipidemia are accompanied by ROS overproduction, lipid peroxidation, and alterations in MAPK and JNK signaling [121, 122]. Patients with metabolic disorders like T2D often have abnormal serum markers of OS [123]. In cell-based T2D models, elevated glucose-induced ROS accumulation and OS result in injury to cardiomyocytes, endothelial cells, and neurons $[124,125]$. Therefore, treatments against OS are indispensable for metabolic diseases. It has been verified that PCs are effective for ameliorating T2D-produced damage of various tissues by increasing pancreatic GSH and reducing lipid peroxidation as well as total nitrate/nitrite levels [126]. Dietary supplementation of PCs dose-dependently prevented the development of hyperglycemia in diabetic obese mice, which suggests that PCs may help control the onset of T2D [127]. Moreover, the levels of total cholesterol, triacylglycerol (TG), low density lipoprotein-cholesterol (LDLC), glutamate pyruvate transaminase, glutamic-oxal(o)acetic transaminase (GOT), and MDA were significantly reduced while SOD and GSH-Px activities were enhanced in a PCtreated liver injury model. This suggests that PCs may protect against high-fat diet-induced fatty liver disease [128].

4.4. Dermatoses. A redox imbalance in the cutaneous microenvironment offers favorable conditions for the initiation and development of skin diseases. Numerous studies have shown that OS contributes to the occurrence and progression of skin photoaging, skin cancer, chloasma, vitiligo, skin trauma, polymorphous light eruption, psoriasis, alopecia areata, atopic dermatitis, and allergic purpura [129-136]. OS can initiate and aggravate dermatoses attacks by damaging DNA, lipids, and proteins, overactivating cytokines/immune mediators, and modifying the activities of Nrf2, MAPK, $\mathrm{NF}-\kappa \mathrm{B} / \mathrm{p} 65$, and PI3K/Akt signaling pathways. As antioxidants, PCs are effective for treating dermatoses by repairing damaged DNA, lipids, and proteins. In addition, PCs control cytokine/immune mediator release and regulate OSrelated signaling pathways. For instance, PCs attenuated UVinduced OS-mediated dermatoses in human skin through suppression of UV-induced OS and activation of NF- $\kappa \mathrm{B}$ and MAPK pathways [40].

4.5. Cancer. OS may cause epigenetic perturbations and mutations by modifying chromatin proteins and damaging DNA [137]. ROS are critical mediators of growth factor receptor signaling and actively participate in cancer cell proliferation [138, 139]. Cancer cells always exhibit accelerated metabolism, and high-level ROS generation is required to maintain their strong proliferation potential. Therefore, targeted regulation of ROS is a promising strategy for cancer therapy [140]. It has been demonstrated that PCs can inhibit proliferation of oral squamous cell carcinoma in a dosedependent manner and reduce the proliferation of cervical cancer cell lines [141]. Moreover, dietary PCs suppressed UVB-induced cutaneous cancer development by promoting the repair of damaged DNA via nuclear excision repair mechanisms and by stimulating DNA repair-dependent immune activity via effector $\mathrm{T}$ cells and dendritic cells [26]. These results underscore the promise of PCs as candidate drugs for the treatment and prevention of cancer.

In addition, OS and related signaling pathways are implicated in numerous additional immune system disorders (e.g., systemic lupus erythematosus [142] and Behcet's disease [143]), urinary system disorders (e.g., uremia) [144], and digestive system diseases (e.g., irritable bowel disease [145]). Further, these disorders may also involve molecules and pathways targeted by PCs, including caspases, PERK/NRF2, NADPH oxidase 4, and JNK/MAPK signaling cascades [146].

\section{Conclusions}

In summary, PCs are natural phytocompounds with potential health benefits, including antioxidant, antimutagenic, antineoplastic, anticytotoxic, and anti-inflammatory activities. Therefore, these agents may be useful for the prevention and treatment of OS-related cardiovascular, neurodegenerative, metabolic, and inflammatory diseases as well as various cancers. Furthermore, compared with synthetic compounds, PCs are readily affordable without side effects. In this review, we summarized the molecular mechanisms and signaling pathways involved in OS, which can be considered as potential targets of PCs treatment. However, more studies about the safety and the effectiveness of different constituents of PCs are needed. Besides, large-sample clinical trials are required. We hope that this review enhances appreciation of the therapeutic potential of PCs against OS-related diseases and that these perspectives facilitate the development of novel PCs-based therapeutic agents.

\section{Disclosure}

Lingyu Yang and Dehai Xian are coauthors.

\section{Conflicts of Interest}

All authors declare that there are no conflicts of interest regarding the publication of this article.

\section{Acknowledgments}

The authors thank Professor Yang Xu and Dr. Yongqiong Deng for their helpful improvement of the quality of this paper.

\section{Supplementary Materials}

The graphical abstract presents a remarkable snapshot of PCs characteristics and its role in mediating oxidative stress as well oxidative stress-associated disorders 
via regulating specific molecules and signaling pathways. (Supplementary Materials)

\section{References}

[1] D. Bagchi, A. Garg, R. L. Krohn, M. Bagchi, M. X. Tran, and S. J. Stohs, "Oxygen free radical scavenging abilities of vitamins $\mathrm{C}$ and $\mathrm{E}$, and a grape seed proanthocyanidin extract in vitro," Research Communications in Molecular Pathology and Pharmacology, vol. 95, no. 2, pp. 179-189, 1997.

[2] D. Bagchi, C. K. Sen, S. D. Ray et al., "Molecular mechanisms of cardioprotection by a novel grape seed proanthocyanidin extract," Mutation Research - Fundamental and Molecular Mechanisms of Mutagenesis, vol. 523-524, pp. 87-97, 2003.

[3] B. Halliwell, "Free radicals and antioxidants: updating a personal view," Nutrition Reviews, vol. 70, no. 5, pp. 257-265, 2012.

[4] D. B. Foster, J. E. Van Eyk, E. Marbán, and B. O’Rourke, "Redox signaling and protein phosphorylation in mitochondria: Progress and prospects," Journal of Bioenergetics and Biomembranes, vol. 41, no. 2, pp. 159-168, 2009.

[5] R. Niranjan, "The Role of inflammatory and oxidative stress mechanisms in the pathogenesis of parkinson's disease: focus on astrocytes," Molecular Neurobiology, vol. 49, no. 1, pp. 28-38, 2014.

[6] M. Schieber and N. S. Chandel, "ROS function in redox signaling and oxidative stress," Current Biology, vol. 24, no. 10, pp. R453-R462, 2014.

[7] B. I. Giasson, J. E. Duda, I. V. J. Murray et al., "Oxidative damage linked to neurodegeneration by selective $\alpha$-synuclein nitration in synucleinopathy lesions," Science, vol. 290, no. 5493, pp. 985989, 2000.

[8] C. Szabó, "The pathophysiological role of peroxynitrite in shock, inflammation, and ischemia-reperfusion injury," Shock, vol. 6, no. 2, pp. 79-88, 1996.

[9] K. K. Griendling and G. A. FitzGerald, "Oxidative stress and cardiovascular injury: PartI: basic mechanisms and in vivo monitoring of ROS," Circulation, vol. 108, no. 16, pp. 1912-1916, 2003.

[10] K. K. Griendling and G. A. FitzGerald, "Oxidative Stress and Cardiovascular Injury: Part II: Animal and Human Studies," Circulation, vol. 108, no. 17, pp. 2034-2040, 2003.

[11] A. Ceriello, "Oxidative stress and diabetes-associated complications," Endocrine Practice, vol. 12, no. 1, pp. 60-62, 2006.

[12] F. Puiggròs, M.-J. Salvadó, C. Bladé, and L. Arola, "Differential Modulation of Apoptotic Processes by Proanthocyanidins as a Dietary Strategy for Delaying Chronic Pathologies," Critical Reviews in Food Science and Nutrition, vol. 54, no. 3, pp. 277291, 2014.

[13] G. Galati, S. Teng, M. Y. Moridani, T. S. Chan, and P. J. O’Brien, "Cancer chemoprevention and apoptosis mechanisms induced by dietary polyphenolics," Drug Metabolism and Drug Interactions, vol. 17, no. 1-4, pp. 311-349, 2000.

[14] F. Gossé, S. Guyot, S. Roussi et al., "Chemopreventive properties of apple procyanidins on human colon cancer-derived metastatic SW620 cells and in a rat model of colon carcinogenesis," Carcinogenesis, vol. 26, no. 7, pp. 1291-1295, 2005.

[15] E. T. Eng, J. Ye, D. Williams et al., "Suppression of Estrogen Biosynthesis by Procyanidin Dimers in Red Wine and Grape Seeds," Cancer Research, vol. 63, no. 23, pp. 8516-8522, 2003.

[16] S. Ray, D. Bagchi, P. M. Lim et al., "Acute and long-term safety evaluation of a novel IH636 grape seed proanthocyanidin extract," Research Communications in Molecular Pathology and Pharmacology, vol. 109, no. 3-4, pp. 165-197, 2001.

[17] Z. Czochanska, L. Y. Foo, R. H. Newman, and L. J. Porter, "Polymeric proanthocyanidins. Stereochemistry, structural units, and molecular weight," Journal of the Chemical Society, Perkin Transactions 1, vol. 1, pp. 2278-2286, 1980.

[18] V. Freitas and N. Mateus, "Structural features of procyanidin interactions with salivary proteins," Journal of Agricultural and Food Chemistry, vol. 49, no. 2, pp. 940-945, 2001.

[19] J.-W. Nam, R. S. Phansalkar, D. C. Lankin et al., "Subtle Chemical Shifts Explain the NMR Fingerprints of Oligomeric Proanthocyanidins with High Dentin Biomodification Potency," The Journal of Organic Chemistry, vol. 80, no. 15, pp. 7495-7507, 2015.

[20] L. Gu, M. A. Kelm, J. F. Hammerstone et al., "Screening of foods containing proanthocyanidins and their structural characterization using LC-MS/MS and thiolytic degradation," Journal of Agricultural and Food Chemistry, vol. 51, no. 25, pp. 7513-7521, 2003.

[21] I. Spranger, B. Sun, A. M. Mateus, V. T. D. Freitas, and J. M. Ricardo-da-Silva, "Chemical characterization and antioxidant activities of oligomeric and polymeric procyanidin fractions from grape seeds," Food Chemistry, vol. 108, no. 2, pp. 519-532, 2008.

[22] A. Serra, A. MacI, M.-P. Romero et al., "Bioavailability of procyanidin dimers and trimers and matrix food effects in in vitro and in vivo models," British Journal of Nutrition, vol. 103, no. 7, pp. 944-952, 2010.

[23] T. Ariga and M. Hamano, "Radical scavenging action and its mode in procyanidins B-1 and B-3 from azuki beans to peroxyl radicals," Agricultural and Biological Chemistry, vol. 54, no. 10, pp. 2499-2504, 2006.

[24] L. F. Casassa, R. C. Larsen, C. W. Beaver et al., "Impact of extended maceration and regulated deficit irrigation (RDI) in cabernet sauvignon wines: Characterization of proanthocyanidin distribution, anthocyanin extraction, and chromatic properties," Journal of Agricultural and Food Chemistry, vol. 61, no. 26, pp. 6446-6457, 2013.

[25] H.-Y. Lai, Y.-Y. Lim, and K.-H. Kim, "Isolation and characterisation of a proanthocyanidin with antioxidative, antibacterial and anti-cancer properties from fern Blechnum orientale," Pharmacognosy Magazine, vol. 13, no. 49, pp. 31-37, 2017.

[26] S. K. Katiyar, H. C. Pal, and R. Prasad, "Dietary proanthocyanidins prevent ultraviolet radiation-induced non-melanoma skin cancer through enhanced repair of damaged DNA-dependent activation of immune sensitivity," Seminars in Cancer Biology, vol. 46, pp. 138-145, 2017.

[27] X. J. Zhang, C. T. Xia, J. M. Wu, and Z. R. Xie, "Research on procyanidins resources," Journal of Chinese Medicinal Materials, vol. 32, no. 7, pp. 1154-1160, 2009 (Chinese).

[28] M. L. Mateos-Martín, J. Pérez-Jiménez, E. Fuguet, and J. L. Torres, "Profile of urinary and fecal proanthocyanidin metabolites from common cinnamon (Cinnamomum zeylanicum L.) in rats," Molecular Nutrition \& Food Research, vol. 56, no. 4, pp. 671-675, 2012.

[29] M. Urpi-Sarda, I. Garrido, M. Monagas et al., "Erratum: Profile of Plasma and Urine Metabolites After the Intake of Almond [Prunus Dulcis (Mill.) D.A. Webb] Polyphenols in Humans," Journal of Agricultural and Food Chemistry, vol. 57, no. 21, pp. 10134-10142, 2009.

[30] M. Monagas, M. Urpi-Sarda, F. Sánchez-Patán et al., "Insights into the metabolism and microbial biotransformation of dietary 
flavan-3-ols and the bioactivity of their metabolites," Food \& Function, vol. 1, no. 3, pp. 233-253, 2010.

[31] S. Touriño, J. Pérez-Jiménez, M. L. Mateos-Martín et al., "Metabolites in contact with the rat digestive tract after ingestion of a phenolic-rich dietary fiber matrix," Journal of Agricultural and Food Chemistry, vol. 59, no. 11, pp. 5955-5963, 2011.

[32] C. Manach, G. Williamson, C. Morand, A. Scalbert, and C. Rémésy, "Bioavailability and bioefficacy of polyphenols in humans. I. Review of 97 bioavailability studies.", American Journal of Clinical Nutrition, vol. 81, no. S1, pp. 230S-242S, 2005.

[33] A. Scalbert, C. Morand, C. Manach, and C. Rémésy, "Absorption and metabolism of polyphenols in the gut and impact on health," Biomedicine \& Pharmacotherapy, vol. 56, no. 6, pp. 276282, 2002.

[34] T. Bohn, "Dietary factors affecting polyphenol bioavailability," Nutrition Reviews, vol. 72, no. 7, pp. 429-452, 2014.

[35] E. Molinar-Toribio, S. Ramos-Romero, E. Fuguet et al., "Influence of omega-3 PUFAs on the metabolism of proanthocyanidins in rats," Food Research International, vol. 97, pp. 133-140, 2017.

[36] R. P. Feliciano, C. G. Krueger, and J. D. Reed, "Methods to determine effects of cranberry proanthocyanidins on extraintestinal infections: Relevance for urinary tract health," Molecular Nutrition \& Food Research, vol. 59, no. 7, pp. 1292-1306, 2015.

[37] X.-X. Chen, H.-L. Feng, Y.-M. Ding et al., "Structure characterization of proanthocyanidins from Caryota ochlandra Hance and their bioactivities," Food Chemistry, vol. 155, pp. 1-8, 2014.

[38] X.-H. Wang, L.-L. Huang, T.-T. Yu et al., "Effects of oligomeric grape seed proanthocyanidins on heart, aorta, kidney in DOCA-salt mice: role of oxidative stress," Phytotherapy Research, vol. 27, no. 6, pp. 869-876, 2013.

[39] M. Long, S.-H. Yang, J.-X. Han et al., "The protective effect of grape-seed proanthocyanidin extract on oxidative damage induced by zearalenone in kunming mice liver," International Journal of Molecular Sciences, vol. 17, no. 6, article no. 808, 2016.

[40] S. K. Mantena and S. K. Katiyar, "Grape seed proanthocyanidins inhibit UV-radiation-induced oxidative stress and activation of MAPK and NF- $\kappa$ B signaling in human epidermal keratinocytes," Free Radical Biology \& Medicine, vol. 40, no. 9, pp. 1603-1614, 2006.

[41] S. D. Sharma, S. M. Meeran, and S. K. Katiyar, "Dietary grape seed proanthocyanidins inhibit UVB-induced oxidative stress and activation of mitogen-activated protein kinases and nuclear factor- $\kappa \mathrm{B}$ signaling in in vivo SKH-1 hairless mice," Molecular Cancer Therapeutics, vol. 6, no. 3, pp. 995-1005, 2007.

[42] Y. Sun, C. Xiu, W. Liu, Y. Tao, J. Wang, and Y. Qu, "Grape seed proanthocyanidin extract protects the retina against early diabetic injury by activating the Nrf2 pathway," Experimental and Therapeutic Medicine, vol. 11, no. 4, pp. 1253-1258, 2016.

[43] J. Yamakoshi, M. Saito, S. Kataoka, and M. Kikuchi, "Safety evaluation of proanthocyanidin-rich extract from grape seeds," Food and Chemical Toxicology, vol. 40, no. 5, pp. 599-607, 2002.

[44] M. A. Costa, K. Ishida, V. Kaplum et al., "Safety evaluation of proanthocyanidin polymer-rich fraction obtained from stem bark of Stryphnodendron adstringens (BARBATIMO) for use as a pharmacological agent," Regulatory Toxicology and Pharmacology, vol. 58, no. 2, pp. 330-335, 2010.

[45] H. Fujii, B. Sun, H. Nishioka, A. Hirose, and O. I. Aruoma, "Evaluation of the safety and toxicity of the oligomerized polyphenol Oligonol," Food and Chemical Toxicology, vol. 45, no. 3, pp. 378-387, 2007.
[46] A. Sano, "Safety assessment of 4-week oral intake of proanthocyanidin-rich grape seed extract in healthy subjects," Food and Chemical Toxicology, vol. 108, pp. 519-523, 2017.

[47] L.-J. Yang, D.-N. Zhu, Y.-L. Dang, and X. Zhao, "Treatment of condyloma acuminata in pregnant women with cryotherapy combined with proanthocyanidins: Outcome and safety," Experimental and Therapeutic Medicine, vol. 11, no. 6, pp. 23912394, 2016.

[48] Y. S. Bae, H. Oh, S. G. Rhee, and Y. D. Yoo, "Regulation of reactive oxygen species generation in cell signaling," Molecules and Cells, vol. 32, no. 6, pp. 491-509, 2011.

[49] A. A. Alfadda and R. M. Sallam, "Reactive oxygen species in health and disease," Journal of Biomedicine and Biotechnology, vol. 2012, Article ID 936486, 14 pages, 2012.

[50] R. Colavitti, G. Pani, B. Bedogni et al., "Reactive oxygen species as downstream mediators of angiogenic signaling by vascular endothelial growth factor receptor-2/KDR," The Journal of Biological Chemistry, vol. 277, no. 5, pp. 3101-3108, 2002.

[51] N. Jha, J. J. Ryu, E. H. Choi, and N. K. Kaushik, "Generation and Role of Reactive Oxygen and Nitrogen Species Induced by Plasma, Lasers, Chemical Agents, and Other Systems in Dentistry," Oxidative Medicine and Cellular Longevity, vol. 2017, pp. 1-13, 2017.

[52] X. Pi, L. Xie, A. L. Portbury et al., "NADPH oxidase-generated reactive oxygen species are required for stromal cell-derived factor-1 $\alpha$-stimulated angiogenesis," Arteriosclerosis, Thrombosis, and Vascular Biology, vol. 34, no. 9, pp. 2023-2032, 2014.

[53] J. L. Meitzler, S. Antony, Y. Wu et al., "NADPH oxidases: a perspective on reactive oxygen species production in tumor biology," Antioxidants \& Redox Signaling, vol. 20, no. 17, pp. 2873-2889, 2014.

[54] B. Kalyanaraman, G. Cheng, M. Hardy, O. Ouari, B. Bennett, and J. Zielonka, "Teaching the basics of reactive oxygen species and their relevance to cancer biology: Mitochondrial reactive oxygen species detection, redox signaling, and targeted therapies," Redox Biology, vol. 15, pp. 347-362, 2017.

[55] C. M. H. Colitz, J. A. Bomser, and D. F. Kusewitt, "The endogenous and exogenous mechanisms for protection from ultraviolet irradiation in the lens," International Ophthalmology Clinics, vol. 45, no. 1, pp. 141-155, 2005.

[56] D. L. Williams, "Oxidation, antioxidants and cataract formation: A literature review," Veterinary Ophthalmology, vol. 9, no. 5, pp. 292-298, 2006.

[57] J. Zhang, X. Wang, V. Vikash et al., "ROS and ROS-mediated cellular signaling," Oxidative Medicine and Cellular Longevity, vol. 2016, Article ID 4350965, 18 pages, 2016.

[58] H. Zhang, A. M. Gomez, X. Wang, Y. Yan, M. Zheng, and H. Cheng, "ROS regulation of microdomain $\mathrm{Ca}^{2+}$ signalling at the dyads," Cardiovascular Research, vol. 98, no. 2, pp. 248-258, 2013.

[59] J. Egea, I. Fabregat, Y. M. Frapart, P. Ghezzi, A. Görlach, and T. Kietzmann, "European contribution to the study of ROS: A summary of the findings and prospects for the future from the COST action BM1203 (EU-ROS)," Redox Biology, vol. 13, pp. 94162, 2017.

[60] J. Cadet and J. R. Wagner, "DNA base damage by reactive oxygen species, oxidizing agents, and UV radiation," Cold Spring Harbor Perspectives in Biology, vol. 5, no. 2, Article ID a012559, 2013.

[61] J. C. Beani, "Ultraviolet A-induced DNA damage: role in skin cancer," Bulletin de L'Académie Nationale de Médecine, vol. 198, no. 2, pp. 273-295, 2014. 
[62] S. Raha and B. H. Robinson, "Mitochondria, oxygen free radicals, disease and ageing," Trends in Biochemical Sciences, vol. 25, no. 10, pp. 502-508, 2000.

[63] M. A. Birch-Machin and H. Swalwell, "How mitochondria record the effects of UV exposure and oxidative stress using human skin as a model tissue," Mutagenesis, vol. 25, no. 2, pp. 101-107, 2010.

[64] J. A. Nichols and S. K. Katiyar, "Skin photoprotection by natural polyphenols: anti-inflammatory, antioxidant and DNA repair mechanisms," Archives of Dermatological Research, vol. 302, no. 2, pp. 71-83, 2010.

[65] S. Katiyar, C. A. Elmets, and S. K. Katiyar, "Green tea and skin cancer: photoimmunology, angiogenesis and DNA repair," The Journal of Nutritional Biochemistry, vol. 18, no. 5, pp. 287-296, 2007.

[66] S. A. Bakheet, A. M. Alhuraishi, N. O. Al-Harbi et al., "Alleviation of Aflatoxin B1-Induced Genomic Damage by Proanthocyanidins via Modulation of DNA Repair," Journal of Biochemical and Molecular Toxicology, vol. 30, no. 11, pp. 559566, 2016.

[67] M. Vaid, R. Prasad, T. Singh, and S. K. Katiyar, "Dietary grape seed proanthocyanidins inactivate regulatory $\mathrm{T}$ cells by promoting NER-dependent DNA repair in dendritic cells in UVB-exposed skin," Oncotarget , vol. 8, no. 30, pp. 4962549636, 2017.

[68] R. Itri, H. C. Junqueira, O. Mertins, and M. S. Baptista, "Membrane changes under oxidative stress: The impact of oxidized lipids," Biophysical Reviews, vol. 6, no. 1, pp. 47-61, 2014.

[69] A. Mittal, C. A. Elmets, and S. K. Katiyar, "Dietary feeding of proanthocyanidins from grape seeds prevents photocarcinogenesis in SKH-1 hairless mice: relationship to decreased fat and lipid peroxidation," Carcinogenesis, vol. 24, no. 8, pp. 1379-1388, 2003.

[70] L. A. Brennan, G. M. Morris, G. R. Wasson, B. M. Hannigan, and Y. A. Barnett, "The effect of vitamin C or vitamin E supplementation on basal and $\mathrm{H} 2 \mathrm{O} 2$-induced DNA damage in human lymphocytes," British Journal of Nutrition, vol. 84, no. 2 , pp. 195-202, 2000.

[71] Y. Park, S. Nam, H.-J. Yi, H.-J. Hong, and M. Lee, "Dietary n-3 polyunsaturated fatty acids increase oxidative stress in rats with intracerebral hemorrhagic stroke," Nutrition Research, vol. 29, no. 11, pp. 812-818, 2009.

[72] A. Ayala, M. F. Muñoz, and S. Argüelles, "Lipid peroxidation: production, metabolism, and signaling mechanisms of malondialdehyde and 4-hydroxy-2-nonenal," Oxidative Medicine and Cellular Longevity, vol. 2014, Article ID 360438, 31 pages, 2014.

[73] S. B. Nimse and D. Pal, "Free radicals, natural antioxidants, and their reaction mechanisms," RSC Advances, vol. 5, no. 35, pp. 27986-28006, 2015.

[74] A. Fernández-Iglesias, H. Quesada, S. Díaz et al., "Combination of grape seed proanthocyanidin extract and docosahexaenoic acid-rich oil increases the hepatic detoxification by GST mediated GSH conjugation in a lipidic postprandial state," Food Chemistry, vol. 165, pp. 14-20, 2014.

[75] B. Nazima, V. Manoharan, and S. Miltonprabu, "Oxidative stress induced by cadmium in the plasma, erythrocytes and lymphocytes of rats: Attenuation by grape seed proanthocyanidins," Human \& Experimental Toxicology, vol. 35, no. 4, pp. 428-447, 2016.

[76] Z. Chen, T. B. Gibson, F. Robinson et al., "MAP kinases," Chemical Reviews, vol. 101, no. 8, pp. 2449-2476, 2001.
[77] J. M. Kyriakis and J. Avruch, "Mammalian mitogen-activated protein kinase signal transduction pathways activated by stress and inflammation," Physiological Reviews, vol. 81, no. 2, pp. 807$869,2001$.

[78] B. Kaminska, "MAPK signalling pathways as molecular targets for anti-inflammatory therapy-from molecular mechanisms to therapeutic benefits," Biochimica et Biophysica Acta-Proteins and Proteomics, vol. 1754, no. 1-2, pp. 253-262, 2005.

[79] M. A. Bachelor and G. T. Bowden, "UVA-mediated activation of signaling pathways involved in skin tumor promotion and progression," Seminars in Cancer Biology, vol. 14, no. 2, pp. 131138, 2004.

[80] L.-Y. Hsu, C.-Y. Nien, W.-M. Huang, S.-C. Hsu, and T.C. Chang, "Synthesis and protective effects of Bis4-[N,N-di(carboxymethyl) amino]-phenoxyalkane derivatives on UVAinduced production of MMP-1 in Human skin fibroblasts," Chemical and Pharmaceutical Bulletin, vol. 62, no. 9, pp. 867874, 2014.

[81] N. Magné, R. A. Toillon, V. Bottero et al., "NF-kappaB modulation and ionizing radiation: mechanisms and future directions for cancer treatment," Cancer Letters, vol. 231, no. 2, pp. 158-168, 2006.

[82] H. Kim, J. Y. Kim, H. S. Song, K. U. Park, K.-C. Mun, and E. $\mathrm{Ha}$, "Grape seed proanthocyanidin extract inhibits interleukin17-induced interleukin-6 production via MAPK pathway in human pulmonary epithelial cells," Naunyn-Schmiedeberg's Archives of Pharmacology, vol. 383, no. 6, pp. 555-562, 2011.

[83] M. J. Bak, V.-L. Truong, S.-Y. Ko et al., "Antioxidant and hepatoprotective effects of procyanidins from wild grape (Vitis amurensis) seeds in ethanol-induced cells and rats," International Journal of Molecular Sciences, vol. 17, no. 5, article no. 758, 2016.

[84] M.-J. Bak, M. Jun, and W.-S. Jeong, "Procyanidins from wild grape (Vitis amurensis) seeds regulate ARE-mediated enzyme expression via Nrf2 coupled with p38 and PI3K/Akt pathway in HepG2 cells," International Journal of Molecular Sciences, vol. 13, no. 1, pp. 801-818, 2012.

[85] A. Siomek, "NF- $\kappa$ B signaling pathway and free radical impact," Acta Biochimica Polonica, vol. 59, no. 3, pp. 323-331, 2012.

[86] T. Wang, X. Zhang, and J. J. Li, "The role of NF- $\kappa \mathrm{B}$ in the regulation of cell stress responses," International Immunopharmacology, vol. 2, no. 11, pp. 1509-1520, 2002.

[87] S. Schoonbroodt and J. Piette, "Oxidative stress interference with the nuclear factor- $\kappa \mathrm{B}$ activation pathways," Biochemical Pharmacology, vol. 60, no. 8, pp. 1075-1083, 2000.

[88] M. Matsumoto, T. Sudo, T. Saito, H. Osada, and M. Tsujimoto, "Involvement of p38 mitogen-activated protein kinase signaling pathway in osteoclastogenesis mediated by receptor activator of NF- $\kappa$ B ligand (RANKL)," The Journal of Biological Chemistry, vol. 275, no. 40, pp. 31155-31161, 2000.

[89] H. Chu, Q. Tang, H. Huang, W. Hao, and X. Wei, "Grapeseed proanthocyanidins inhibit the lipopolysaccharide-induced inflammatory mediator expression in RAW264.7 macrophages by suppressing MAPK and NF- $\kappa$ b signal pathways," Environmental Toxicology and Pharmacology, vol. 41, pp. 159-166, 2016.

[90] P. Limtrakul, S. Yodkeeree, P. Pitchakarn, and W. Punfa, "Antiinflammatory effects of proanthocyanidin-rich red rice extract via suppression of MAPK, AP-1 and NF- $\kappa$ B pathways in Raw 264.7 macrophages," Nutrition Research and Practice, vol. 10, no. 3, pp. 251-258, 2016.

[91] J.-W. Lee, Y. I. Kim, C.-N. Im et al., "Grape Seed Proanthocyanidin Inhibits Mucin Synthesis and Viral Replication by 
Suppression of AP-1 and NF- $\kappa$ B via p38 MAPKs/JNK Signaling Pathways in Respiratory Syncytial Virus-Infected A549 Cells," Journal of Agricultural and Food Chemistry, vol. 65, no. 22, pp. 4472-4483, 2017.

[92] A. Giudice, C. Arra, and M. C. Turco, "Review of molecular mechanisms involved in the activation of the Nrf2-ARE signaling pathway by chemopreventive agents," Methods in Molecular Biology, vol. 647, pp. 37-74, 2010.

[93] G. P. Sykiotis and D. Bohmann, "Stress-activated cap'n'collar transcription factors in aging and human disease," Science Signaling, vol. 3, no. 112, p. re3, 2010.

[94] H.-C. Huang, T. Nguyen, and C. B. Pickett, "Regulation of the antioxidant response element by protein kinase C-mediated phosphorylation of NF-E2-related factor 2," Proceedings of the National Acadamy of Sciences of the United States of America, vol. 97, no. 23, pp. 12475-12480, 2000.

[95] K. Itoh, J. Mimura, and M. Yamamoto, "Discovery of the negative regulator of Nrf2, keapl: a historical overview," Antioxidants \& Redox Signaling, vol. 13, no. 11, pp. 1665-1678, 2010.

[96] R. M. Tyrrell, "Solar ultraviolet A radiation: An oxidizing skin carcinogen that activates heme oxygenase-1," Antioxidants \& Redox Signaling, vol. 6, no. 5, pp. 835-840, 2004.

[97] A. K. MacLeod, M. Mcmahon, S. M. Plummer et al., "Characterization of the cancer chemopreventive NRF2-dependent gene battery in human keratinocytes: demonstration that the KEAP1NRF2 pathway, and not the BACH1-NRF2 pathway, controls cytoprotection against electrophiles as well as redox-cycling compounds," Carcinogenesis, vol. 30, no. 9, pp. 1571-1580, 2009.

[98] M. Long, Y. Liu, Y. Cao, N. Wang, M. Dang, and J. He, "Proanthocyanidins attenuation of chronic lead-induced liver oxidative damage in kunming mice via the Nrf2/ARE pathway," Nutrients, vol. 8, no. 10, article no. 656, 2016.

[99] C. Sun, W. Jin, and H. Shi, "Oligomeric proanthocyanidins protects A549 cells against $\mathrm{H} 2 \mathrm{O} 2$-induced oxidative stress via the Nrf2-ARE pathway," International Journal of Molecular Medicine, vol. 39, no. 6, pp. 1548-1554, 2017.

[100] B. Cai, J.-P. Cai, Y.-L. Luo, C. Chen, and S. Zhang, “The Specific Roles of JAK/STAT Signaling Pathway in Sepsis," Inflammation, vol. 38, no. 4, pp. 1599-1608, 2015.

[101] A. C. Dudley, D. Thomas, J. Best, and A. Jenkins, "The STATs in cell stress-type responses," Cell Communication and Signaling, vol. 2, article no. 8, 2004.

[102] X. Jin, Z. Xu, R. Fan et al., "HO-1 alleviates cholesterol-induced oxidative stress through activation of Nrf2/ERK and inhibition of PI3K/AKT pathways in endothelial cells," Molecular Medicine Reports, vol. 16, no. 3, pp. 3519-3527, 2017.

[103] C. G. Song, X. Yang, L. Q. Min, C. X. Liu, and C. S. Zhao, "The effect of procyanidin on expression of STAT1 in type 2 diabetes mellitus SD rats with focal cerebral ischemia," Neuroendocrinology Letters, vol. 35, no. 1, pp. 68-72, 2014.

[104] L. Wang, L.-H. Zhu, H. Jiang et al., "Grape seed proanthocyanidins attenuate vascular smooth muscle cell proliferation via blocking phosphatidylinositol 3-kinase-dependent signaling pathways," Journal of Cellular Physiology, vol. 223, no. 3, pp. 713-726, 2010.

[105] E. M. Putz, D. Gotthardt, G. Hoermann et al., "CDK8-mediated STAT1-S727 phosphorylation restrains NK cell cytotoxicity and tumor surveillance," Cell Reports, vol. 4, no. 3, pp. 437-444, 2013.

[106] P.-H. Shih and G.-C. Yen, "Differential expressions of antioxidant status in aging rats: the role of transcriptional factor $\mathrm{Nrf} 2$ and MAPK signaling pathway," Biogerontology, vol. 8, no. 2, pp. 71-80, 2007.
[107] J. H. Lim, H.-S. Park, J.-K. Choi, I.-S. Lee, and J. C. Hyun, "Isoorientin induces Nrf2 pathway-driven antioxidant response through phosphatidylinositol 3-kinase signaling," Archives of Pharmacal Research, vol. 30, no. 12, pp. 1590-1598, 2007.

[108] M. N. Sack, F. Y. Fyhrquist, O. J. Saijonmaa, V. Fuster, and J. C. Kovacic, "Basic Biology of Oxidative Stress and the Cardiovascular System: Part 1 of a 3-Part Series," Journal of the American College of Cardiology, vol. 70, no. 2, pp. 196-211, 2017.

[109] T. Münzel, G. G. Camici, C. Maack, N. R. Bonetti, V. Fuster, and J. C. Kovacic, "Impact of Oxidative Stress on the Heart and Vasculature: Part 2 of a 3-Part Series," Journal of the American College of Cardiology, vol. 70, no. 2, pp. 212-229, 2017.

[110] P. Pignatelli, V. Sanguigni, L. Lenti et al., "Oxidative stressmediated platelet CD40 ligand upregulation in patients with hypercholesterolemia: Effect of atorvastatin," Journal of Thrombosis and Haemostasis, vol. 5, no. 6, pp. 1170-1178, 2007.

[111] L.-L. Huang, C. Pan, L. Wang et al., "Protective effects of grape seed proanthocyanidins on cardiovascular remodeling in DOCA-salt hypertension rats," The Journal of Nutritional Biochemistry, vol. 26, no. 8, pp. 841-849, 2015.

[112] Z. Pons, L. Guerrero, M. Margalef, L. Arola, A. Arola-Arnal, and B. Muguerza, "Effect of low molecular grape seed proanthocyanidins on blood pressure and lipid homeostasis in cafeteria diet-fed rats," Journal of Physiology and Biochemistry, vol. 70, no. 2, pp. 629-637, 2014.

[113] T. C. Sutcliffe, A. N. Winter, N. C. Punessen, and D. A. Linseman, "Procyanidin B2 Protects Neurons from Oxidative, Nitrosative, and Excitotoxic Stress," Antioxidants (Basel), vol. 6, no. 4, p. 77, 2017.

[114] A. Reynolds, C. Laurie, R. Lee Mosley, and H. E. Gendelman, "Oxidative stress and the pathogenesis of neurodegenerative disorders," International Review of Neurobiology, vol. 82, pp. 297-325, 2007.

[115] M. Pinot, S. Vanni, S. Pagnotta et al., "Polyunsaturated phospholipids facilitate membrane deformation and fission by endocytic proteins," Science, vol. 345, no. 6197, pp. 693-697, 2014.

[116] J. Z. Nowak, "Oxidative stress, polyunsaturated fatty acidsderived oxidation products and bisretinoids as potential inducers of CNS diseases: Focus on age-related macular degeneration," Pharmacological Reports, vol. 65, no. 2, pp. 288-304, 2013.

[117] N. Nakano, S. Matsuda, M. Ichimura et al., "PI3K/AKT signaling mediated by $\mathrm{G}$ protein-coupled receptors is involved in neurodegenerative Parkinson's disease (Review)," International Journal of Molecular Medicine, vol. 39, no. 2, pp. 253-260, 2017.

[118] C. Dong, "Protective Effect of Proanthocyanidins in Cadmium Induced Neurotoxicity in Mice," Drug Research, vol. 65, no. 10, pp. 555-560, 2015.

[119] D. Bagchi, M. Bagchi, S. J. Stohs et al., "Free radicals and grape seed proanthocyanidin extract: importance in human health and disease prevention," Toxicology, vol. 148, no. 2-3, pp. 187$197,2000$.

[120] K. E. Strathearn, G. G. Yousef, M. H. Grace et al., "Neuroprotective effects of anthocyanin-and proanthocyanidinrich extractsin cellular models of Parkinson's disease," Brain Research, vol. 1555, pp. 60-77, 2014.

[121] D. Pesta and M. Roden, "The Janus Head of Oxidative Stress in Metabolic Diseases and During Physical Exercise," Current Diabetes Reports, vol. 17, no. 6, article no. 41, 2017.

[122] K. M. Stepien, R. Heaton, S. Rankin et al., "Evidence of Oxidative Stress and Secondary Mitochondrial Dysfunction in Metabolic and Non-Metabolic Disorders," Journal of Clinical Medicine, vol. 6, no. 7, pp. 1-25, 2017. 
[123] S. Kurban, I. Mehmetoglu, H. F. Yerlikaya, S. Gönen, and S. Erdem, "Effect of chronic regular exercise on serum ischemiamodified albumin levels and oxidative stress in type 2 diabetes mellitus," Endocrine Research, vol. 36, no. 3, pp. 116-123, 2011.

[124] Y. Lee, Y. Hong, S. R. Lee, and K. T. Chang, "Autophagy contributes to retardation of cardiac growth in diabetic rats," Laboratory Animal Research, vol. 28, no. 2, pp. 99-107, 2012.

[125] D. Barthelmes, L. Zhu, W. Shen, M. C. Gillies, and M. R. Irhimeh, "Differential gene expression in Lin-/VEGF-R2 ${ }^{+}$bone marrow-derived endothelial progenitor cells isolated from diabetic mice," Cardiovascular Diabetology, vol. 13, no. 1, article 42, 2014.

[126] A. T. El-Alfy, A. A. E. Ahmed, and A. J. Fatani, "Protective effect of red grape seeds proanthocyanidins against induction of diabetes by alloxan in rats," Pharmacological Research, vol. 52, no. 3, pp. 264-270, 2005.

[127] M. Tomaru, H. Takano, N. Osakabe et al., "Dietary supplementation with cacao liquor proanthocyanidins prevents elevation of blood glucose levels in diabetic obese mice," Nutrition Journal , vol. 23, no. 4, pp. 351-355, 2007.

[128] Q. Xuan, Y. X. Zhang, D. G. Liu et al., "Effect of proanthocyanidins on preventing and treating high-fat diet induced fatty liver in rats," Journal of Chinese Practical Diagnosis and Therapy, vol. 30, no. 9, pp. 848-850, 2016 (Chinese).

[129] J. Wenk, P. Brenneisen, C. Meewes et al., "UV-induced oxidative stress and photoaging," Current Problems in Dermatology, vol. 29, pp. 83-94, 2001.

[130] S. N. Arun, I. Kaddour-Djebbar, B. A. Shapiro, and W. B. Bollag, "Ultraviolet B irradiation and activation of protein kinase D in primary mouse epidermal keratinocytes," Oncogene, vol. 30, no. 13, pp. 1586-1596, 2011.

[131] D. Massi, A. Franchi, I. Sardi et al., "Inducible nitric oxide synthase expression in benign and malignant cutaneous melanocytic lesions," The Journal of Pathology, vol. 194, no. 2, pp. 194-200, 2001.

[132] D. Agrawal, E. M. Shajil, Y. S. Marfatia, and R. Begum, "Study on the antioxidant status of vitiligo patients of different age groups in Baroda," Pigment Cell Research, vol. 17, no. 3, pp. 289-294, 2004.

[133] R. Moseley, J. R. Hilton, R. J. Waddington, K. G. Harding, P. Stephens, and D. W. Thomas, "Comparison of oxidative stress biomarker profiles between acute and chronic wound environments," Wound Repair and Regeneration, vol. 12, no. 4, pp. 419-429, 2004.

[134] F. Rippke, G. Wendt, K. Bohnsack et al., "Results of photoprovocation and field studies on the efficacy of a novel topically applied antioxidant in polymorphous light eruption," Journal of Dermatological Treatment, vol. 12, no. 1, pp. 3-8, 2001.

[135] B. E. Prie, V. M. Voiculescu, O. B. Ionescu-Bozdog et al., "Oxidative stress and alopecia areata," Journal of Medicine and Life, vol. 8, pp. 43-46, 2015.

[136] H. Ji and X.-K. Li, "Oxidative Stress in Atopic Dermatitis," Oxidative Medicine and Cellular Longevity, vol. 2016, Article ID 2721469, 2016.

[137] M. P. Pruchniak, M. Aražna, and U. Demkow, "Biochemistry of oxidative stress," Advances in Experimental Medicine and Biology, vol. 878, pp. 9-19, 2016.

[138] Q. Felty, K. P. Singh, and D. Roy, "Estrogen-induced G1/S transition of G0-arrested estrogen-dependent breast cancer cells is regulated by mitochondrial oxidant signaling," Oncogene, vol. 24, no. 31, pp. 4883-4893, 2005.
[139] G. Waris and H. Ahsan, "Reactive oxygen species: role in the development of cancer and various chronic conditions," Journal of Carcinogenesis, vol. 5, article 14, 2006.

[140] V. Sosa, T. Moliné, R. Somoza, R. Paciucci, H. Kondoh, and M. E. LLeonart, "Oxidative stress and cancer: an overview," Ageing Research Reviews, vol. 12, no. 1, pp. 376-390, 2013.

[141] M. King, K. Chatelain, D. Farris et al., "Oral squamous cell carcinoma proliferative phenotype is modulated by proanthocyanidins: A potential prevention and treatment alternative for oral cancer," BMC Complementary and Alternative Medicine, vol. 7, article no. 22, 2007.

[142] J. Frostegård, E. Svenungsson, R. Wu et al., "Lipid peroxidation is enhanced in patients with systemic lupus erythematosus and is associated with arterial and renal disease manifestations," Arthritis \& Rheumatology, vol. 52, no. 1, pp. 192-200, 2005.

[143] C. Yazici, K. Köse, M. Çaliş, M. Demir, M. Kirnap, and F. Ateş, "Increased advanced oxidation protein products in Behçet's disease: a new activity marker?" British Journal of Dermatology, vol. 151, no. 1, pp. 105-111, 2004.

[144] F. Floccari, C. Aloisi, E. Crascí et al., "Oxidative stress and uremia," Medicinal Research Reviews, vol. 25, no. 4, pp. 473-486, 2005.

[145] Y. Dincer, Y. Erzin, S. Himmetoglu, K. N. Gunes, K. Bal, and T. Akcay, "Oxidative DNA damage and antioxidant activity in patients with inflammatory bowel disease," Digestive Diseases and Sciences, vol. 52, no. 7, pp. 1636-1641, 2007.

[146] J. Kumar, S. L. Teoh, S. Das, and P. Mahakknaukrauh, “Oxidative stress in oral diseases: Understanding its relation with other systemic diseases," Frontiers in Physiology, vol. 8, article no. 693, 2017. 


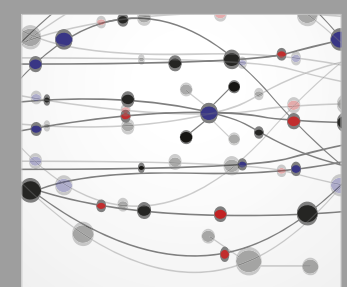

The Scientific World Journal
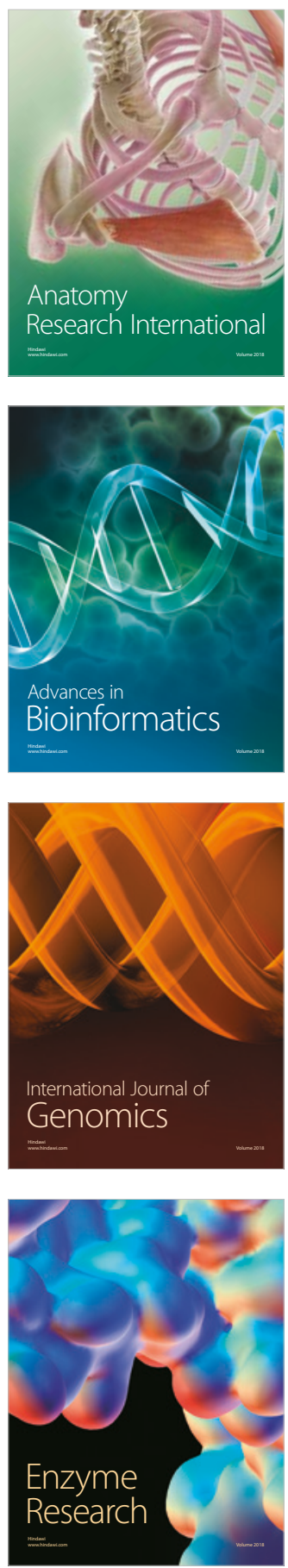
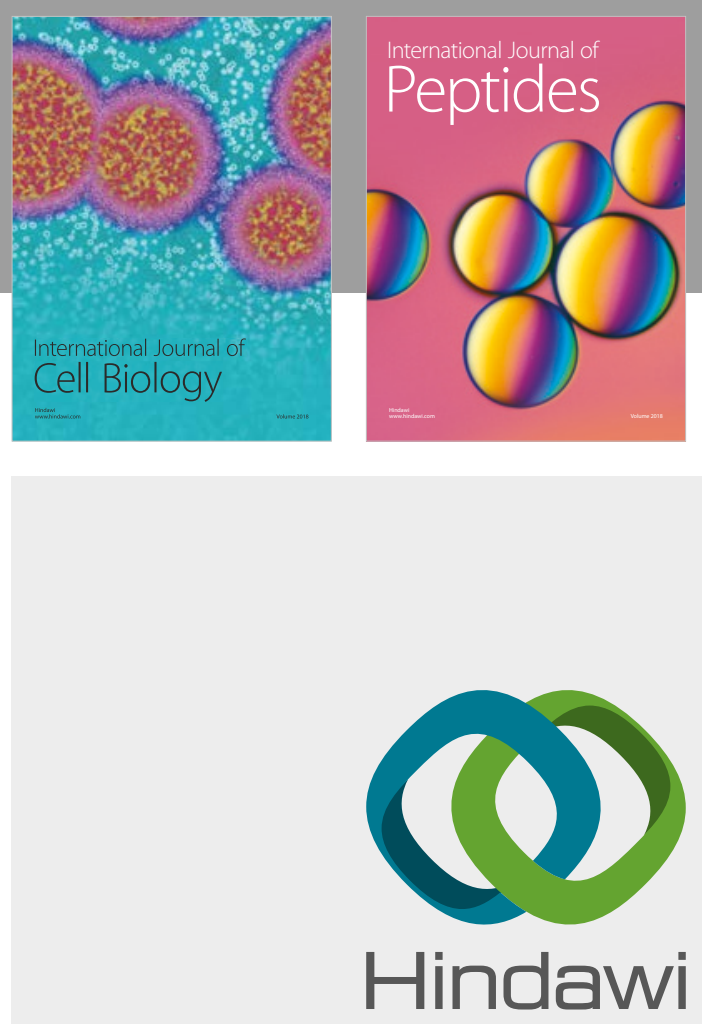

Submit your manuscripts at

www.hindawi.com
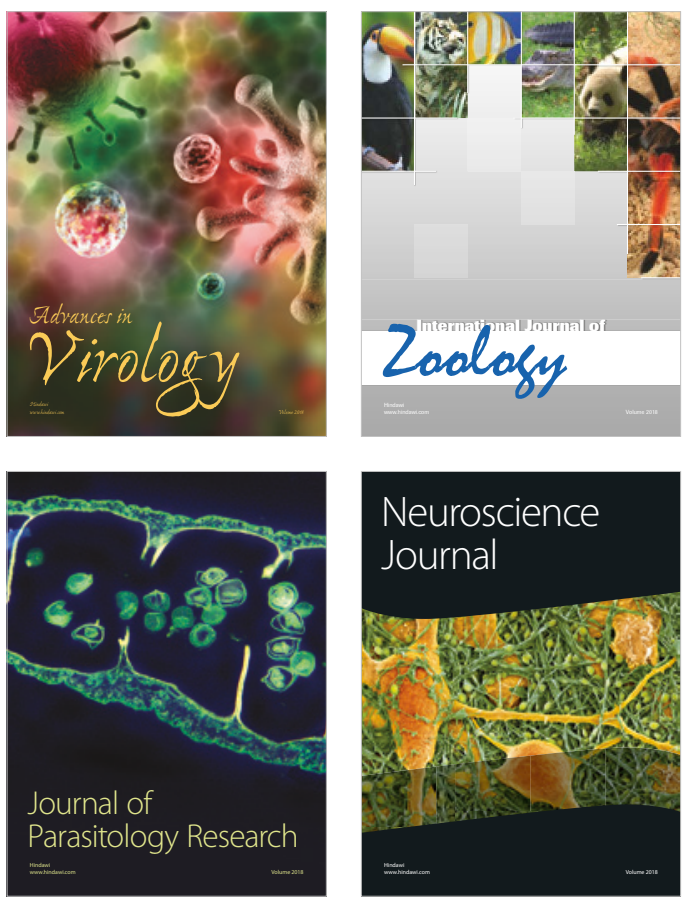
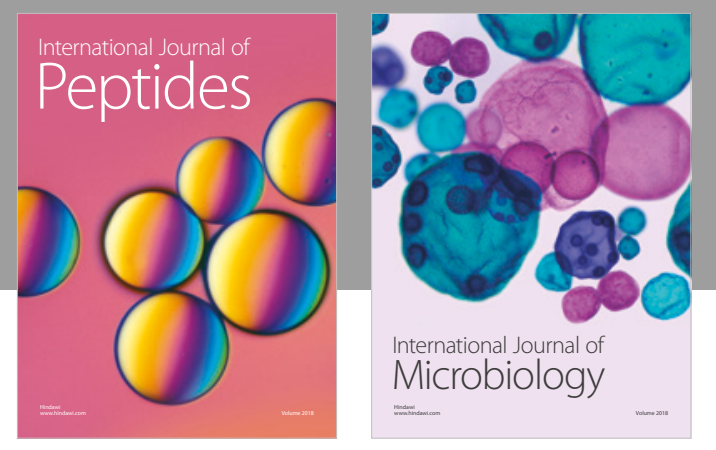

nternational Journal of Microbiology
Journal of
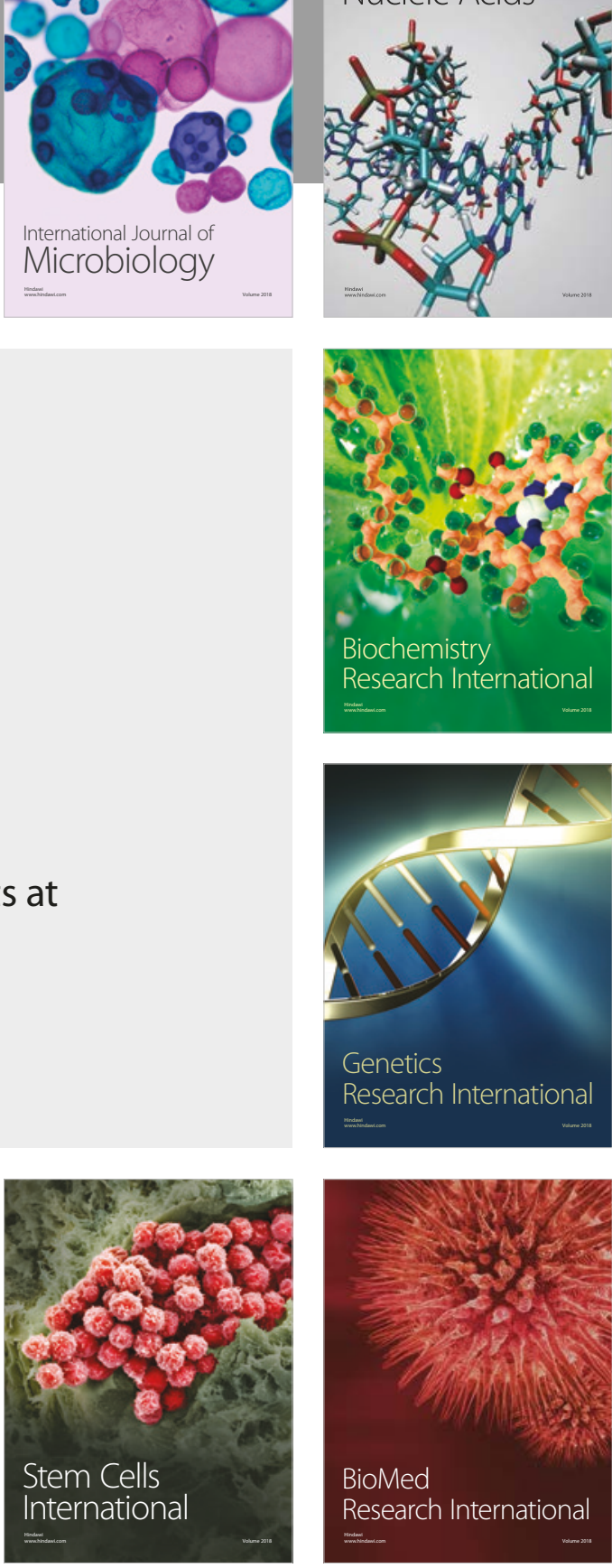
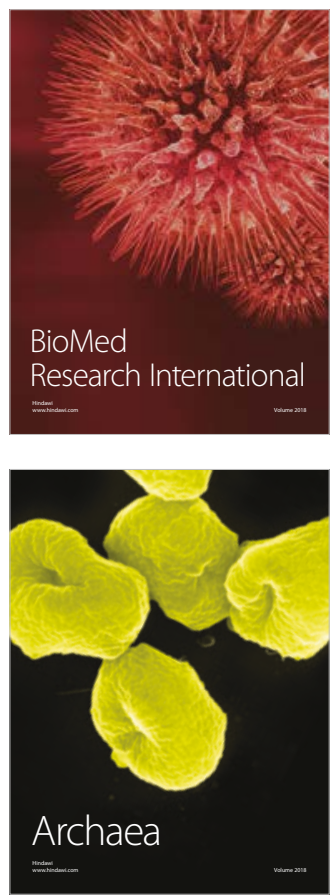